\title{
Regulation of Voltage and Reactive Power Based on the Control of Lead- ing Phase Operation of Generator
}

\author{
Wei Yan-fang ${ }^{1,2, *}$, Zheng Zheng ${ }^{1}$, Sun Yan-zhou ${ }^{1}$, Zhang Tao ${ }^{1}$, Si Ji-kai ${ }^{1}$ and Wang Xiao-wei ${ }^{1}$ \\ ${ }^{1}$ School of Electrical Engineering and Automation, Henan Polytechnic University, Jiaozuo, China \\ ${ }^{2}$ Key Laboratory of Control Engineering of Henan Province, Henan Polytechnic University, Jiaozuo, China
}

\begin{abstract}
Leading phase operation of generator is an effective method for the control and regulation of voltage and reactive power of power system. The ability of voltage regulation for key buses by control of generator is presented in this paper. The PSD-BPA software - Power System Analysis Software Package (PSD-BPA) is introduced firstly. The management database for leading phase operation of generator is discussed. From the lagging phase operation to leading phase operation of generator, the change curves of voltage for main $500 \mathrm{kV}$ bus and $220 \mathrm{kV}$ bus are analyzed. The sensitivity on voltage regulation of each generator of leading phase operation is given. Based on the analysis of short circuit fault of power plant, the limit output power of leading phase operation of multi-generators is proposed. The leading phase operation of generator has many advantages, such as easy to operate, simple and feasible implement, and the actual operation is safe and reliable. The technique was worthy to be widely used.
\end{abstract}

Keywords: Voltage regulation, reactive power, leading phase operation of generator, PSD-BPA.

\section{INTRODUCTION}

Voltage is an important index of weighing the power quality. The operation level of voltage is closely related with the balance of reactive power. Generator is the main source of reactive power in the power system. The voltage and reactive power control of generator is an essential measure to ensure the balance between voltage quality and reactive power, and can improve reliability and economy operation of power system $[1,2]$.

With the construction and development of ultra high voltage, large capacity, long distance transmission of modern power grid, the overhead lines and cable lines of ultra high voltage increased a lot. The capacitance of line to line and line to ground is increasing, which causes the capacitor current and capacitive reactive power growing. When the system load is at a low level, especially on holidays and midnight time, the reactive power generated by line is surplus. When the charging reactive power greater than the reactive load, the load voltage is high. The effect makes the voltage of some pivot points becoming too high, close to or more than the voltage limits of system operation. The safe operation of electric power equipment and user equipment is seriously affected.

Compared with the conventional compensation equipment of reactive power, synchronous generator has many advantages, such as smooth regulating of voltage, no need for additional equipment investment, bidirectional compen- sating of reactive power, and so on. Considered from the perspective of economic operation, the leading phase operation of generator is a flexible and feasible means of voltage regulation [3-5]. In the present stage, the leading phase operation of generator still has unmatchable advantage over other way of voltage regulation. When the excitation condition of generator changes, the generator is controlled to send active power and absorb reactive power at the same time, and balancing adjustment of reactive power and voltage of the system is also achieved. The leading phase operation of generator has obvious social and economic benefit [6-7]. The regulation of voltage and reactive power based on the control of leading phase operation of generator is discussed in this paper.

\section{PSD-BPA SOFTWARE}

The PSD-BPA software - Power System Analysis Software Package (PSD-BPA) is a product of China Electric Power Research Institute (CEPRI) [8-9]. It is software of Chinesization and second development by CEPRI, and has been widely used in the Chinese power network. The main functions of PSD-BPA are shown in Fig. (1). As shown in Fig. (1), the software mainly includes basic power flow and transient stability analysis of power system.

\section{DATABASE FOR LEADING PHASE OPERA- TION OF GENERATOR}

At present, there are many successful engineering practice of leading phase operation of generator in China. And a large number of experimental data are obtained. The data types are briefly summarized as follows. 


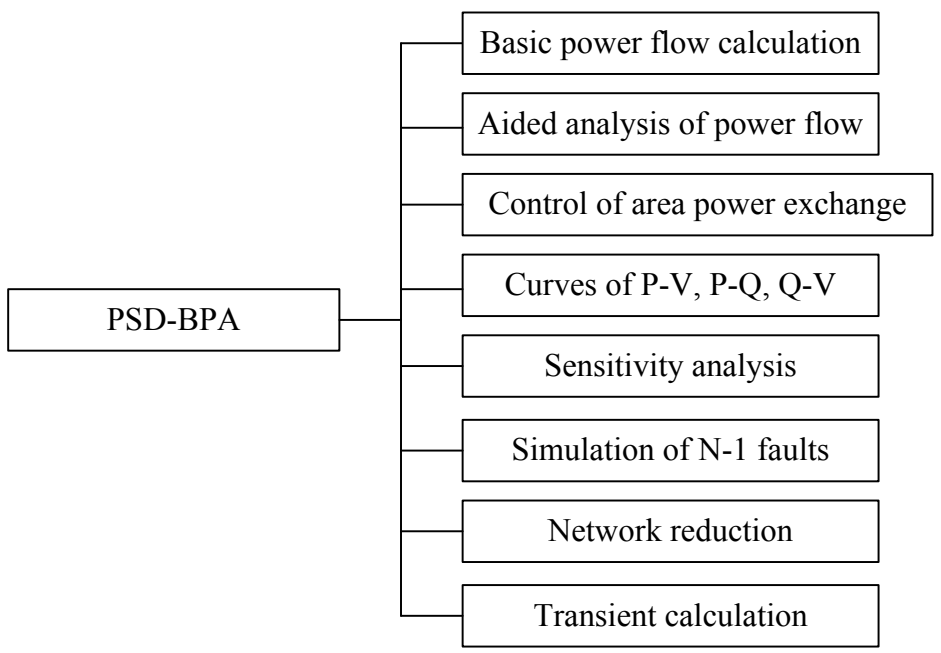

Fig. (1). Main functions of PSD-BPA.

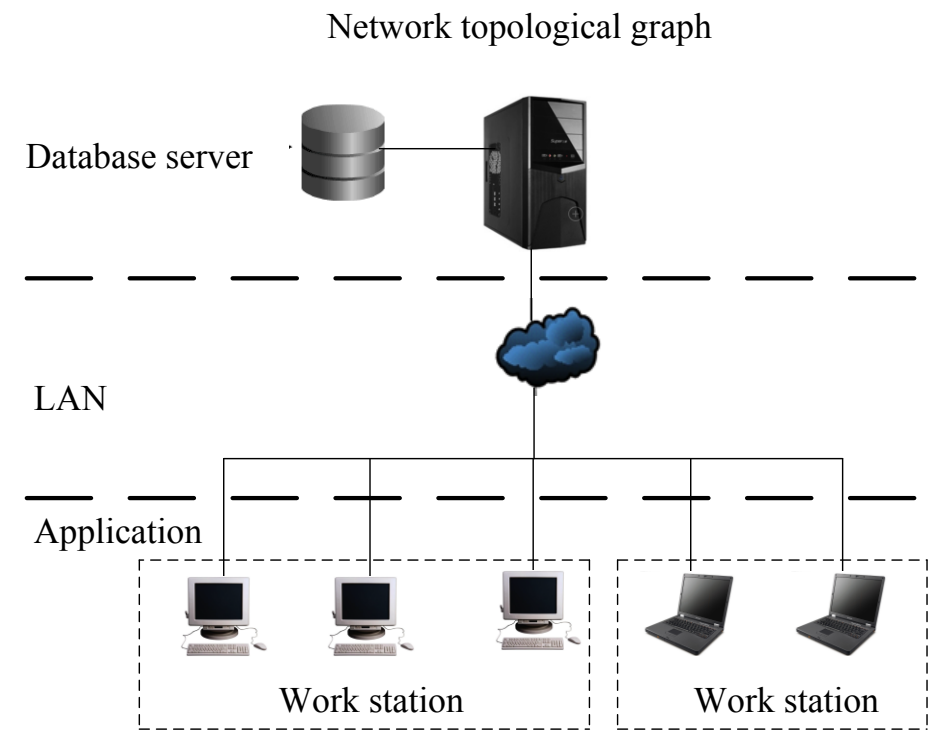

Fig. (2). Topological graph of system network.

1) The power plant data include: main electrical wiring of primary power system, fluctuation range of bus voltage, unit operation time, manufacturer of generator, the time of putting into operation, etc.

2) The generator data include: type, rated capacity, rated power, stator voltage, stator current, rotor voltage, rotor current, power factor, end voltage of generator, etc.

3) The regulator data of excitation include: excitation mode, type, limit value setting of low excitation, strong excitation ratio, low excitation protection, etc.

4) The single data of generator include: testing time of zero position of power angle, test time of leading phase operation, time of passed evaluation, etc.

At present, there are lots of test dada for leading phase operation of generators, such as limit conclusion, statistic summary, limit value of low excitation, and so on. Now the sharing of the test dada is not convenience. It is necessary to built management database for leading phase operation of generator. The database can maintain and manage integrally. And the operation personnel can use the database conveniently $[10,11]$. According to the management database of leading phase operation of generator, the management of leading phase operation, the coordination of plant and gird, the richness database of grid and the promotion of control ability of grid are improved. The topological graph of system network is shown in Fig. (2). As can be seen in Fig. (2), there are three layers of the system network, the database server layer, the LAN layer and the application layer.

\section{VOLTAGE REGULATION OF LEADING PHASE OPERATION OF GENERATOR}

The effect of voltage regulating on power system can be represented by the following coefficient $[12,13]$. 


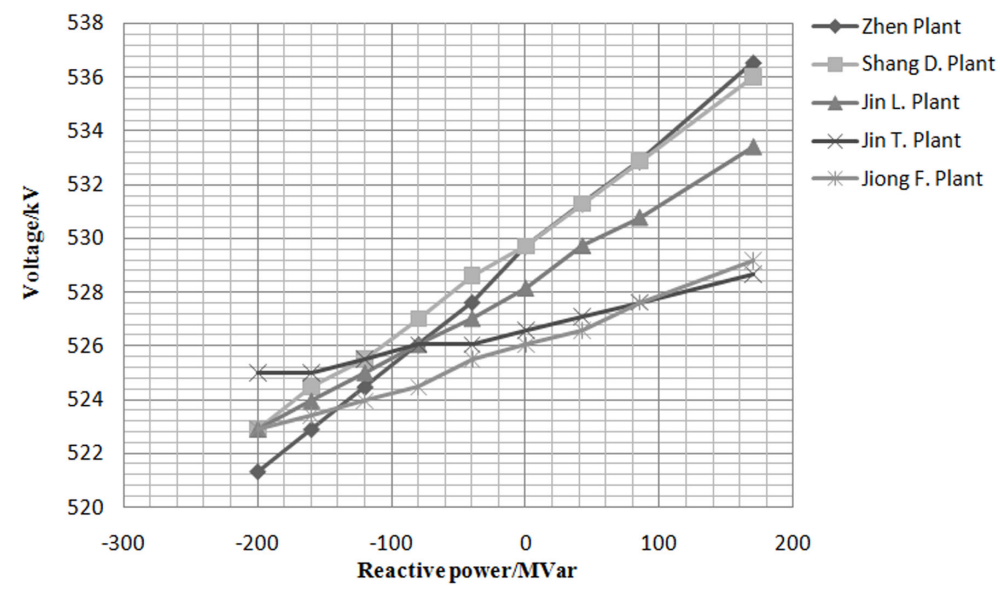

Fig. (3). Effect on the $500 \mathrm{kV}$ bus voltage level of the leading phase operation of No. 5 and 6 .

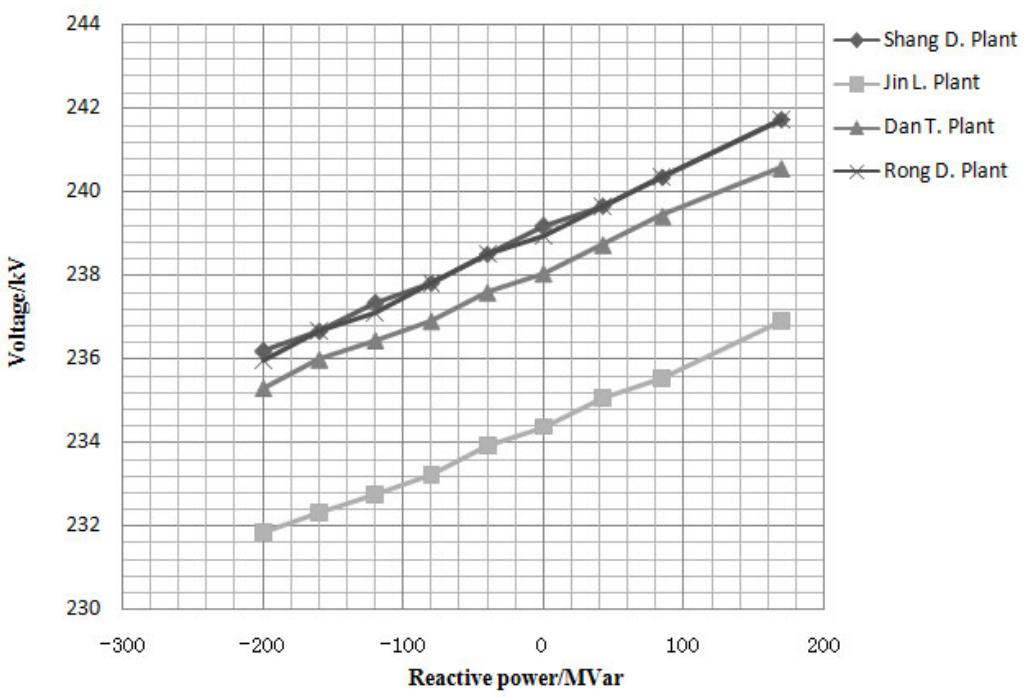

Fig. (4). Effect on the $220 \mathrm{kV}$ bus voltage level of the leading phase operation of No. 5 and 6.

$$
K_{Q}=\frac{\Delta V}{\Delta Q}
$$

$\boldsymbol{K}_{\boldsymbol{Q}}$ is defined as regulation coefficient. The unit of the coefficient is V/MVar. $\boldsymbol{K}_{\boldsymbol{Q}}$ denotes the voltage variation according to the variation of $1 \mathrm{MV}$ ar for reactive power.

Based on the BPA software, the model of leading phase operation of generator is built. The voltage changing curve of $500 \mathrm{kV}$ bus and $220 \mathrm{kV}$ bus, the regulating effect on system voltage of each unit of leading phase operation are discussed.

\section{1) Effect on the Bus Voltage Level of the Leading Phase Operation of Generator}

The No. 5 generator and No. 6 generator of Zhen Plant are chosen to be analyzed. According to the average allocation of reactive power output of the two generators, the influence on each bus voltage of station $\mathrm{s}$ by leading phase operation of generator are shown in Fig. (3) and Fig. (4).
As shown by the above analysis and calculation, the Zhen Plant No. 5 and 6 generators are in leading phase operation. The reactive power outputs of the two generators are the same. When the operating condition of generators changed, seen in Fig. (3 and 4), form sending 112.7MVar to absorbing 100MVar, the voltage of $500 \mathrm{kV}$ bus of Shang D. Station dropped to $522.9 \mathrm{kV}$. The voltage of $500 \mathrm{kV}$ bus of Zhen Plant Station dropped to $521.325 \mathrm{kV}$. The voltage of $220 \mathrm{kV}$ bus of Shang D. Station dropped to $236.21 \mathrm{kV}$. The bigger voltage drop is $15 \mathrm{kV}$. Simulation results shown that the obvious effect of voltage regulation of leading phase of multi-generators.

\section{2) Voltage Regulation Coefficient of Leading Phase Op- eration of Generator}

The voltage regulation coefficients of leading phase operation of generator for Zhen Plant 5 and 6 are shown in Table 1. 
Table 1. Bus regulation coefficient of No. 5 and 6 generator in leading phase operation.

\begin{tabular}{|c|c|c|c|c|c|c|c|c|c|}
\hline \multirow{2}{*}{$\begin{array}{c}\mathbf{Q}_{G} \\
\text { (MVar) }\end{array}$} & \multicolumn{9}{|c|}{$\Delta V / \Delta Q(V / M V a r)$} \\
\cline { 2 - 11 } & Zhen Plant & Shang D. Plant & Jin L. Plant & Jin T. Plant & Jiong F. Plant & Shang D. Plant & Jin L. Plant & Dan T. Plant & Rong D. Plant \\
\hline \hline 85 & 43.2 & 37.1 & 30.9 & 12.4 & 18.5 & 16.2 & 16.2 & 13.5 \\
\hline 42.5 & 37.1 & 37.1 & 24.7 & 12.4 & 24.7 & 16.2 & 10.8 & 16.2 & 16.2 \\
\hline 0 & 37.1 & 37.1 & 37.1 & 12.4 & 12.4 & 10.8 & 16.2 & 16.2 & 16.2 \\
\hline-40 & 52.5 & 27.5 & 28.5 & 13.1 & 13.1 & 17.2 & 11.5 & 11.5 & 11.5 \\
\hline-80 & 39.4 & 40.4 & 24.0 & 0.0 & 26.2 & 17.2 & 17.2 & 17.2 & 17.2 \\
\hline-120 & 39.4 & 37.1 & 26.2 & 13.1 & 13.1 & 11.5 & 11.5 & 11.5 & 17.2 \\
\hline-160 & 39.4 & 26.2 & 26.2 & 13.1 & 13.1 & 17.3 & 11.5 & 11.5 & 11.5 \\
\hline-200 & 39.4 & 39.4 & 26.3 & 0.0 & 13.1 & 11.5 & 11.5 & 17.2 & 17.2 \\
\hline
\end{tabular}

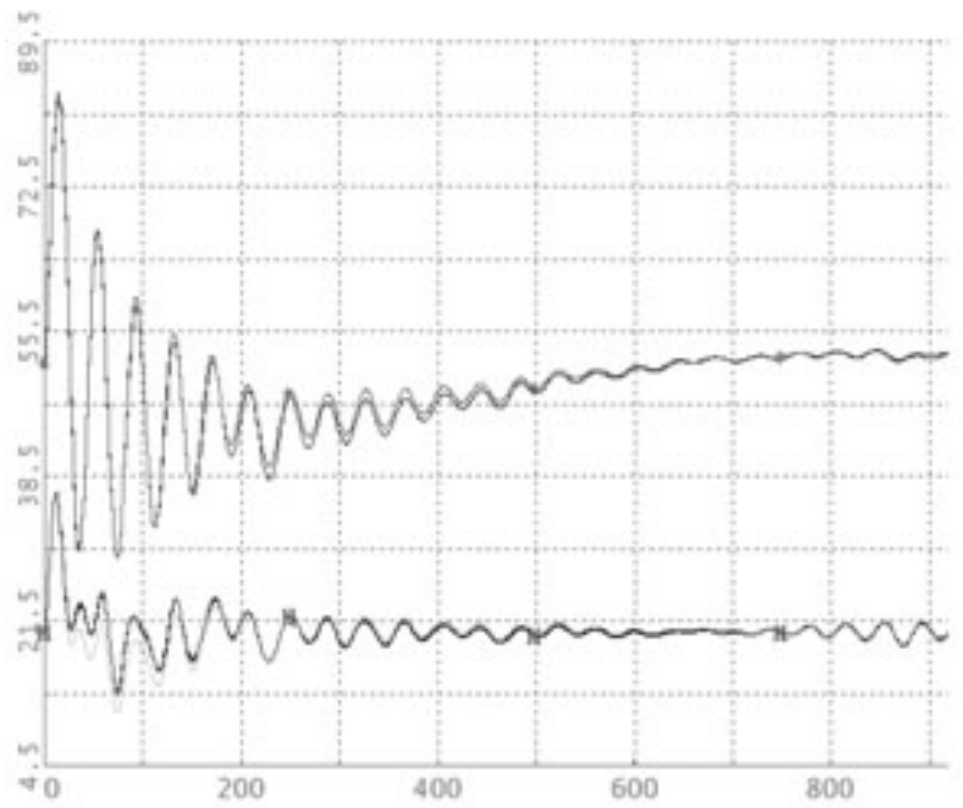

(Power angle of Zhen Plant No. 1-6 generators)

Fig. (5). Curves of relative power angle under three phase fault of $500 \mathrm{kV}$ bus between Zhen Plant and Shang D. Plant.

As can be seen in Table 1, for the $500 \mathrm{kV}$ bus, by the leading phase of Zhen Plant No. 5 and 6 generators, the voltage regulation effect of Zhen Plant Station and Shang D. Plant Station are more obvious than other plants.

\section{3) Stability Analysis}

The three-phase short circuit fault at Zhen Plant $500 \mathrm{kV}$ bus is set. From 0 to 5 cycle, the transient stability of the leading phase at $-200 \mathrm{MV}$ ar is verified. The relative power factor of each generator is shown in Fig. (5) (Hua X. Plant No. 1 is chosen as reference machine).
As can be seen in Fig. (5), the three-phase short-circuit fault is set at $500 \mathrm{kV}$ bus between Zhen Plant and Shang D. Plant. The transient stability of the system is verified. In Fig. (5), after the fault clearing at 0.2 second, the relative power angle of each generator can maintain stable.

\section{CONCLUSION}

The regulation of voltage and reactive power based on the control of leading phase operation of generator is discussed in this paper. The necessary and importance of the building of management database for leading phase 
operation of generator is analyzed. The effectiveness on voltage adjustment for $500 \mathrm{kV}$ and $220 \mathrm{kV}$ bus by leading phase operation of generator is remarkable. But the effect of voltage regulation on distant bus is not very obvious. The voltage regulation mode of combining of multi-generators, multi-plants and static compensation devices is still a key research hotspot for the following work.

\section{CONFLICT OF INTEREST}

The authors confirm that this article content has no conflict of interest.

\section{ACKNOWLEDGEMENTS}

This work was financially supported in part by the National Natural Science Foundation of China (Grant no. 61340015, 61403127, and U1204506) in part by the Key Project of Science and Technology of the Education Department Henan Province (Grant no. 14A470001, 12B470003 and 14A470004), in part by the Key Laboratory of Control Engineering of Henan Province (no. KG2014-04), and in part by the Research Fund for the Doctoral Program of Henan Polytechnic University (no. B2014-023).

\section{REFERENCES}

[1] L. Z. Pan, J. Yin, Q. Cheng and Z. D. Xie, "Research and Application Promotion of Automatic Voltage Control System s for Generating Units", East China Electric Power, vol. 37, no. 9, pp. 1510-1513, 2009.

[2] Yin, "Application of Automatic Reactive Power Regulation and Control Devices to AVC System", East China Electric Power, vol. 33, no. 9, pp. 7-10, 2005.
[3] Y. F. Wei, Z. N. Wei, Y. Q. Zhang, G. Q. Sun, C. L. Wang and Y. H. Sun, "Progress and Development Trend on Leading Phase of Generator", Power System Protection and Control, vol. 40, no. 9, pp. 146-154, 2012.

[4] W. Yan, J. Chen and Q. R. Shen, "Discussion on Large Non salient Pole Generator Phase advancement Operation", Automation of Electric Power Systems, vol. 31, no. 2, pp. 94-97, 2007.

[5] W. Q. Xiang and S. Q. Sheng, "A reconfiguration algorithm for complex distribution networks based on reliability index", Relay, vol. 33, no. 20, pp. 53-56, 73, 2005.

[6] J. Y. Shi, Y. S. Shi, X. M. Zhao, S. L. Qu, Y. H. Guo and L. Zhang, "The New Method of Determining the Capability of Leading Phase of Generator and Realizing the On-Line Monitoring", Proceedings of the CSEE, vol. 26, no. 11, pp. 139-143, 2006.

[7] C. L. Wang, H. H. Wang and C. M. Xiang, "Generator Leading Phase Ability Model Based on RBF Neural Network", Transactions of China Electrotechnical Society, vol. 27, no. 1, pp. 124-129, 2012.

[8] Y. Tang, G. Q. Bu and J. X. Qiu; User Guide of PSD-BPA (4.10 Version). Beijing: China Electric Power Research Institute, 2008.

[9] Y. Yi, B. L. Chang, L. Li, Z. D. Bi, T. Xin and W. Tan, "Automatic Batch Generation and Modification of PSD-BPA Datacards for Power Flow Calculation", Automation of Electric Power Systems, vol. 37, no. 10, pp. 124-128, 2005.

[10] L. Y. Jiang, Z. N. Wei, C. L. Wang and F. Yu, "Database Development for Leading Phase Operation Management of Power Generators based on B/S Mode", Jiangsu Electrical Engineering, vol. 29, no. 6, pp. 78-80, 2010.

[11] Y. F. Wei, Z.N.Wei, G. Q. Sun, W. W. Hu and Y. H. Sun, "Discussion of Several Issues of Leading Phase Operation of Multigenerators", Journal of Hohai University (Natural Sciences), vol. 40, no. 5, pp. 590-596, 2012.

[12] J. B. Guo, Z. P. Zhang, Z. P. Shan, D. X. Xia, G. L. Xiang and F. L. Tu, "Technical and Economic Comparison and Adjustment Research of Reactive Voltage in Leading Phase", Hunan Electric Power, no. 21, pp. 19-23, 2001.

[13] Y. F. Wei, Z. N. Wei, G. Q. Sun and C. L. Wang, "Voltage Regulation Effects of Leading Phase Operation of Multi-generators in District Grids", East China Electric Power, vol. 39, no. 9, pp. 1434-1438, 2005.

Received: October 16, 2014

(C) Yan-fang et al.; Licensee Bentham Open.

This is an open access article licensed under the terms of the Creative Commons Attribution Non-Commercial License (http://creativecommons.org/licenses/by$\mathrm{nc} / 3.0 /$ ) which permits unrestricted, non-commercial use, distribution and reproduction in any medium, provided the work is properly cited. 